\title{
Pólipos da vesícula biliar no idoso
}

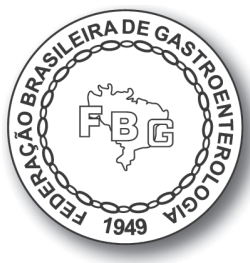

Júlio C. U. Coelho

Mônica Beatriz Parolin

Antonio C. L. Campos

\section{INTRODUÇÃO}

Pólipo da vesícula biliar é definido como qualquer lesão que se projeta na superfície da mucosa. É uma condição comum, quase sempre benigna, assintomática e diagnosticada incidentalmente durante a realização de um exame de imagem abdominal. Poucos pólipos da vesícula biliar podem evoluir para carcinoma, uma neoplasia de elevada mortalidade. O diagnóstico e o tratamento precoces desses pólipos pré-malignos são fundamentais para prevenir a sua progressão para carcinoma.

\section{INCIDÊNCIA E ASPECTOS EPIDEMIOLÓGICOS}

A incidência de pólipos da vesícula biliar é extremamente variável na literatura, dependendo do método diagnóstico utilizado: exame patológico, ultrassonografia, tomografia computadorizada (TC) ou ressonância magnética (RM). A incidência relatada na maioria das grandes séries publicadas varia de 1 a $12 \%$.

Os pólipos ocorrem em qualquer idade, mas são mais comuns entre os $30 \mathrm{e}$ 60 anos de idade. Apesar dos cálculos biliares predominarem no sexo feminino, os pólipos da vesícula biliar são um pouco mais comuns nos homens, em uma proporção de 1,2 a 1,5 homens por 1 mulher.

A incidência de malignidade nos pólipos da vesícula biliar é desconhecida. Em pólipos ressecados, geralmente pólipos $>10 \mathrm{~mm}$ ou com características pré-malignas, a incidência de malignidade varia de 1 a $20 \%$.

Pacientes com síndromes e polipose intestinais congênitas, como polipose múltipla familiar, síndrome de Peutz-Jeghers e síndrome de Gardner, apresen- 
tam maior incidência de pólipos da vesícula biliar. Os pólipos da vesícula biliar também são mais comuns em pacientes com leucodistrofia metacromática e colangite esclerosante primária. Nesta última afecção, a porcentagem de malignidade nestes pólipos é muito elevada, podendo atingir 40 a 60\%.

\section{CLASSIFICAÇÃO}

Os pólipos da vesícula biliar podem ser classificados em não neoplásicos (mais comuns) e neoplásicos (Tabela 1). O pólipo mais frequente é o pólipo de colesterol, correspondendo a 60 a 70\% dos pólipos da vesícula biliar. Este pólipo é pequeno (4 a $10 \mathrm{~mm}$ em diâmetro) e decorre da infiltração de macrófagos ricos em colesterol na lâmina própria da mucosa. O pólipo pode ser único, mas frequentemente é múltiplo.

Os pólipos neoplásicos podem ser benignos, pré-malignos e malignos. Os adenomas são os pólipos neoplásicos mais comuns e correspondem a somente 5\% dos pólipos da vesícula biliar. Apesar de incomuns, estes pólipos são importantes de serem reconhecidos e tratados, pelo potencial de evoluírem para carcinoma, principalmente os adenomas $>1 \mathrm{~cm}$.

\begin{tabular}{ll} 
Tabela 1 Classificação dos pólipos da vesícula biliar \\
\hline Pólipos não neoplásicos & \begin{tabular}{l} 
Pólipos de colesterol \\
\hline Tecidos ectópicos: gástrico, pancreático ou hepático
\end{tabular} \\
\hline Pólipos inflamatórios \\
\hline Adenoma \\
\hline Carcinoma \\
\hline Carcinoide \\
\hline Neuroma \\
\hline Fibroma e fibroadenoma \\
\hline Lipoma \\
\hline Angioma \\
\hline Metástase
\end{tabular}

\section{MANIFESTAÇÕES CLÍNICAS}

A quase totalidade dos pólipos de vesícula biliar é assintomática. Entretanto, em casos raros, o pólipo pode se desprender da mucosa e obstruir o ducto cístico causando cólica biliar ou, mais raramente, colecistite aguda. A passagem do pólipo através do ducto cístico, e posteriormente pela papila maior (papila de Vater), pode causar pancreatite aguda. 
Pólipos maiores localizados no colo da vesícula biliar também podem causar cólica biliar e colecistite aguda, mesmo sem seu desprendimento. Nesta situação, o pólipo pode, pela sua localização e dimensões, obstruir o colo da vesícula ou o próprio ducto cístico.

\section{DIAGNÓSTICO}

Os pólipos são geralmente identificados durante a realização de um exame de imagem de rotina como uma estrutura que se projeta na superfície interna da parede da vesícula biliar. A diferenciação entre pólipo e cálculo pequeno pode ser difícil. À ultrassonografia, os pólipos não produzem sombra acústica e são fixos à parede da vesícula biliar (Figura 1). Ao contrário, cálculos pequenos quase sempre produzem sombra acústica e são móveis à mudança de posição do paciente durante o exame.

Apesar de outros exames de imagem, como ecoDoppler, TC, RM, ultrassonografia tridimensional, ultrassonografia de alta resolução, imagem harmônica e ecoendoscopia, poderem contribuir para a melhora da precisão na diferenciação entre pólipos malignos e benignos, o papel desses exames na indicação de colecistectomia em pacientes com pólipos da vesícula biliar permanece controverso. Estes métodos aumentam a precisão do diagnóstico de pólipos malignos $>10 \mathrm{~mm}$, mas têm baixa precisão para pólipos menores. Além do mais, custo elevado e potenciais complicações destes exames são outros fatores limitantes na sua indicação. Atualmente, o grupo de consenso de várias especialidades europeias de pólipos da vesícula biliar não recomenda o seu uso de rotina na avaliação de pacientes com pólipo de vesícula biliar".

A realização adicional de Doppler durante a ultrassonografia abdominal pode aumentar a precisão na identificação de pólipos pré-malignos ou ma-

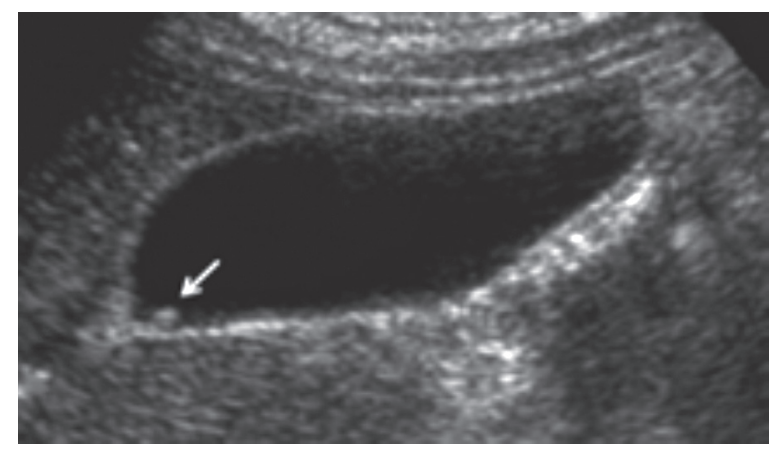

Figura 1 Ultrassonografia abdominal evidenciando um pólipo de vesícula biliar de $2 \mathrm{~mm}$ (seta). 
lignos. Estes pólipos são vascularizados. A ultrassonografia endoscópica e a de alta resolução são os melhores exames de imagem para a diferenciação de pólipo benigno de pólipo maligno. Entretanto, a sensibilidade destes exames ultrassonográficos para estabelecer o diagnóstico de carcinoma em pólipos < $10 \mathrm{~mm}$ é de somente cerca de $45 \%$.

\section{CONDUTA}

A conduta em pacientes com pólipos de vesícula biliar depende de alguns aspectos clínicos e de características do pólipo na ultrassonografia. A quase totalidade dos pólipos é assintomática, benigna e não necessita colecistectomia. Entretanto, os poucos pólipos que são malignos ou com potencial de malignização são quase sempre neoplásicos ou se tornarão neoplasias com mortalidade elevada (90 a 95\%) se não tratados precocemente. Assim, é fundamental identificar este pequeno número de pacientes com pólipos pré-malignos e malignos para estabelecer o tratamento precoce.

Um aspecto de maior importância na conduta do pólipo de vesícula biliar é o seu potencial de se tornar maligno (carcinoma). Apesar de incomum, o carcinoma da vesícula biliar é biologicamente agressivo e de mau prognóstico. A única expectativa de cura é o diagnóstico precoce. Este fato enaltece a importância do reconhecimento de condições pré-malignas e o seu tratamento como pólipo de potencial maligno.

A hipótese da evolução adenoma $\rightarrow$ adenoma com displasia $\rightarrow$ carcinoma de vesícula biliar tem sido sugerida pelo achado frequente de focos de displasia e de adenocarcinoma in situ na mucosa circunjacente ao carcinoma invasivo da vesícula biliar. Com base nestes achados, alguns autores sugeriram que a maioria dos carcinomas da vesícula é proveniente de pólipos pré-malignos. Embora esta teoria tenha sido amplamente comprovada em cerca de $90 \%$ dos pacientes com carcinoma colônico, a evolução adenoma $\rightarrow$ carcinoma parece ser incomum nos pacientes com carcinoma da vesícula biliar, como demonstrado em vários estudos clinicopatológicos e moleculares recentes.

\section{LIMITAÇÕES DOS ESTUDOS SOBRE PÓLIPOS DA VESÍCULA BILIAR}

Avaliando os estudos científicos na literatura, constata-se ausência de consenso na conduta sobre pólipos da vesícula biliar em razão dos seguintes aspectos:

- A grande maioria dos estudos refere-se a uma casuística com pequeno número de pacientes. 
- O acompanhamento dos pacientes é curto.

- Existem vários tipos de pólipos de vesícula, com características e evolução clínica distintas.

- A grande maioria dos pacientes não é submetida à colecistectomia e, portanto, carece de confirmação diagnóstica do tipo de pólipo.

\section{FATORES DE RISCO PARA CARCINOMA}

Algumas características clínicas e de exames de imagem dos pólipos podem contribuir para a identificação de pólipos malignos ou com potencial de se tornarem malignos. A avaliação da presença destes fatores é essencial no processo decisório de conduta terapêutica. A decisão deve ser tomada com base no conjunto destes fatores de risco. As principais características que sugerem o diagnóstico de pólipo maligno ou de se tornarem malignos são:

- Tamanho do pólipo: o risco de malignidade em pólipos $>10 \mathrm{~mm}$ é bem superior aos pólipos menores. Pólipos $>10 \mathrm{~mm}$ têm um risco de malignidade 25 vezes maior que pólipos $<10 \mathrm{~mm}$. É incomum a ocorrência de malignidade em pólipos com diâmetro entre 6 e $10 \mathrm{~mm}$, exceto em pacientes com outros fatores de risco, como colangite esclerosante primária e idade $>50$ a 60 anos. Pólipos $\leq 5 \mathrm{~mm}$ são quase sempre benignos (Figura 2).

- Número de pólipos: a grande maioria dos pólipos malignos é única ou em número inferior a 3. A presença de pólipos múltiplos sugere o diagnóstico de pólipos de colesterol, uma condição sempre benigna.

- Crescimento do pólipo: o crescimento significante $(>2 \mathrm{~mm})$ de pólipo durante a realização de ultrassonografia seriada sugere o diagnóstico de pólipo maligno ou pré-maligno.

- Pólipo séssil ou pediculado: o risco de malignidade dos pólipos é significativamente maior nos sésseis do que nos pediculados.

- Idade do paciente: a possibilidade de pólipo maligno é maior em indivíduos com mais de 50 a 60 anos.

- Associação com cálculo da vesícula biliar: a associação de pólipo à colecistolítiase aumenta o risco de malignidade.

- Pacientes com colangite esclerosante primária: a incidência de adenocarcinoma em pólipos da vesícula biliar de pacientes com colangite esclerosante primária é bastante expressiva, cerca de 40 a $60 \%$.

- Descendentes de índios têm um aumento expressivo na porcentagem de malignidade nos pólipos de vesícula biliar (5,5\% versus $0,08 \%$ em brancos). 
- A dosagem do CEA e CA 19-9 tem muito baixa precisão na diferenciação entre pólipo maligno e benigno de pequenas dimensões $(<1$ a $2 \mathrm{~cm})$.

\section{INDICAÇÕES DE COLECISTECTOMIA LAPAROSCÓPICA}

Apesar de não haver consenso, a maioria dos autores indica colecistectomia em pacientes com pólipo de vesícula biliar nas seguintes condições:

- Pólipos sintomáticos (cólica biliar, colecistite aguda, pancreatite aguda).

- Pólipos $>10 \mathrm{~mm}$.

- Pacientes $>50$ a 60 anos de idade com pólipos $>5 \mathrm{~mm}$.

- Pólipos associados com cálculos.

- Pólipos que aumentam de tamanho (> $2 \mathrm{~mm}$ ).

- Pólipos em paciente com colangite esclerosante primária, independentemente do tamanho.

Apesar de incomum, a colangite esclerosante primária é associada a uma elevada incidência de colangiocarcinoma e adenocarcinoma da vesícula biliar. Em virtude da expressiva incidência de adenocarcinoma em pólipos da vesícula biliar (40 a 60\%), tanto a Associação Europeia para o Estudo do Fígado como a Associação Americana para o Estudo das Doenças do Fígado recomendam que todos os pacientes com colangite esclerosante primária devem ser submetidos a ultrassonografia abdominal a cada 6 meses para identificação de pólipos da vesícula biliar. Estas duas associações recomendam que todos os pacientes

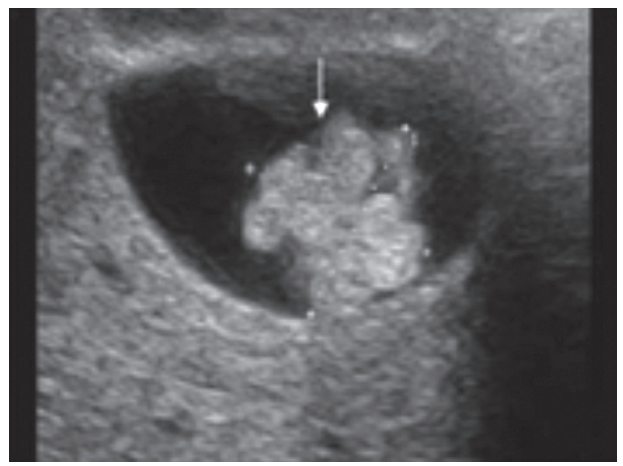

Figura 2 Ultrassonografia abdominal mostrando um pólipo de vesícula biliar de $2 \mathrm{~cm}$ e de superfície irregular (seta). $\bigcirc$ exame anatomopatológico confirmou o diagnóstico de adenocarcinoma de vesícula biliar. 
com colangite esclerosante primária que apresentam pólipo da vesícula biliar, independentemente do tamanho, devem ser submetidos à colecistectomia.

\section{INDICAÇÕES AMPLIADAS DE COLECISTECTOMIA NO IDOSO}

Além das indicações anteriormente mencionadas, alguns autores ampliaram a indicação de colecistectomia para os pacientes com mais de 50 a 60 anos de idade que apresentam pólipo de vesícula biliar entre 5 e $10 \mathrm{~mm}$ por causa da maior prevalência de carcinoma da vesícula biliar acima desta faixa etária.

Como a grande maioria dos carcinomas da vesícula biliar ocorre após os 50 a 60 anos de idade, muitos consideram que o pólipo da vesícula em pacientes com mais de 50 a 60 anos de idade deve ser considerado como de maior risco de malignização. Recentemente, a diretriz do consenso de várias sociedades científicas europeias estabeleceu que a idade maior do que 50 anos é um fator de risco para carcinoma em pacientes com pólipos de vesícula. Esta diretriz sugere que pacientes com $>50$ anos de idade com pólipos entre 5 e $10 \mathrm{~mm}$ devem ser submetidos à colecistectomia. Entretanto, os especialistas destas diretrizes reconhecem que esta decisão é baseada mais em consenso entre os especialistas do que em critérios científicos.

\section{PROCEDIMENTO CIRÚRGICO}

Atualmente, a colecistectomia laparoscópica é o método preferencial para o tratamento de pólipos da vesícula biliar. Após a exérese da vesícula biliar, ela deve ser avaliada pelo cirurgião. Em caso de suspeita de malignidade, o pólipo deve ser avaliado por exame de anatomia patológica de congelação peroperatório. Se houver comprovação de malignidade e o carcinoma for de estágio superior a Tla (tumor que invade a lâmina própria), a operação deve ser convertida para a via aberta e o procedimento deve ser ampliado. Devem ser adicionados ressecção hepática em cunha do leito da vesícula e linfadenectomia.

Alguns autores sugerem colecistectomia por via aberta associada ressecção hepática em cunha do leito da vesícula e linfadenectomia para pacientes com pólipos $>18 \mathrm{~mm}$, pelo risco significante de adenocarcinoma com estádio superior a T1a.

\section{ACOMPANHAMENTO DOS PACIENTES COM ULTRASSONOGRAFIA PERIÓDICA}

Para os pacientes com pólipo de vesícula em que não está indicada a colecistectomia, deve-se realizar acompanhamento dos pacientes com ultrassono- 
grafia periódica. O objetivo do acompanhamento ou vigilância dos pólipos é fornecer segurança para os pacientes com pólipos verdadeiros $<10 \mathrm{~mm}$ que não podem ser diferenciados dos pólipos não neoplásicos na ultrassonografia. Os pólipos $\geq 10 \mathrm{~mm}$ não necessitam de acompanhamento, pois a colecistectomia está indicada, exceto em pacientes que recusam o procedimento ou apresentam contraindicação à cirurgia. Pólipos que apresentam características ultrassonográficas típicas de um pólipo não neoplásico (adenomatose focal ou pólipo de colesterol) com artefato de reverberação posterior ("cauda de cometa”) não necessitam de acompanhamento com ultrassonografia periódica.

Não existe consenso sobre o tamanho dos pólipos que necessitam de acompanhamento, bem como a frequência e a duração desse acompanhamento. Um aspecto de consenso é que a ultrassonografia deve ser o exame de acompanhamento a ser realizado periodicamente.

Apesar da maioria dos autores evidenciar que pólipos da vesícula pré-malignos são geralmente maiores do que $5 \mathrm{~mm}$, alguns casos de pólipos verdadeiros menores do que $5 \mathrm{~mm}$ que se transformaram em carcinoma em poucos anos foram adequadamente documentados na literatura.

Com o objetivo de padronizar o acompanhamento dos pacientes com pólipos da vesícula biliar, um grupo de especialistas de várias sociedades científicas europeias realizou uma reunião de consenso em 2017 para estabelecer algumas importantes diretrizes, as quais são resumidas a seguir. $\mathrm{O}$ acompanhamento com ultrassonografia está indicado nas seguintes condições:

- Se o paciente não tiver fator de risco para carcinoma de vesícula e o pólipo for de 6 a $9 \mathrm{~mm}$. A ultrassonografia de acompanhamento deve ser realizada no $6^{\circ}$ mês, após 1 ano e, posteriormente, a cada ano até 5 anos.

- Se o paciente tiver fator de risco para carcinoma de vesícula e o pólipo for $\leq 5 \mathrm{~mm}$. A ultrassonografia de acompanhamento deve ser realizada no $6^{\circ}$ mês, após 1 ano e, posteriormente, a cada ano até 5 anos.

- Se o paciente não tiver fator de risco para carcinoma de vesícula e o pólipo for $\leq 5 \mathrm{~mm}$. A ultrassonografia de acompanhamento deve ser realizada após 1 ano, 3 anos e 5 anos.

- Se durante o acompanhamento o pólipo crescer $\geq 2 \mathrm{~mm}$, a colecistectomia deve ser realizada.

- Se durante o acompanhamento o pólipo alcançar $10 \mathrm{~mm}$, a colecistectomia deve ser realizada.

- Se durante o acompanhamento o pólipo desaparecer, o acompanhamento deve ser descontinuado.

- Se após 5 anos de acompanhamento o pólipo não crescer, ele é considerado não neoplásico e não existe indicação de continuar o acompanhamento. 


\section{CONSIDERAÇÕES FINAIS}

Embora o pólipo da vesícula biliar seja comum, a grande maioria é benigna, assintomática e não necessita tratamento.

A sensibilidade e a especificidade dos exames de imagem para predizer se o pólipo é pré-maligno ou maligno são baixas.

A colecistectomia laparoscópica é indicada nos pacientes com pólipo de vesícula biliar nas seguintes condições:

- Pólipo $>10 \mathrm{~mm}$.

- Pacientes $>50$ a 60 anos de idade com pólipos $>5 \mathrm{~mm}$.

- Pólipo associado a cálculo.

- Pólipo que aumenta de tamanho (> $2 \mathrm{~mm}$ ).

- Pacientes com colangite esclerosante primária, independentemente do tamanho do pólipo.

A colecistectomia laparoscópica é o método preferencial para o tratamento de pólipos da vesícula biliar.

Nos pacientes com pólipo de vesícula em que não está indicada a colecistectomia, deve-se realizar acompanhamento com ultrassonografia periódica. A frequência de realização da ultrassonografia depende do tamanho e da presença de fatores de risco.

\section{REFERÊNCIAS BIBLIOGRÁFICAS}

1. Elmasry M, Lindop D, Dunne DF, Malik H, Poston GJ, Fenwick SW. The risk of malignancy in ultrasound detected gallbladder polyps: a systematic review. Int J Surg. 2016;33 Pt A:28-35.

2. McCain RS, Diamond A, Jones C, Coleman HG. Current practices and future prospects for the management of gallbladder polyps: a topical review. World J Gastroenterol. 2018;24(26):2844-52.

3. Svassi-Rocha AL, Savassi-Rocha PR. Colesterolose, pólipos e adenomiomatose da vesícula biliar. In: Coelho JCU. Aparelho digestivo. Clínica e cirurgia. 4.ed. Rio de Janeiro: Atheneu; 2012. p.1825-32.

4. Wiles R, Thoeni RF, Barbu ST, Vashist YK, Rafaelsen SR, Dewhurst C, et al. Management and follow-up of gallbladder polyps: Joint guidelines between the European Society of Gastrointestinal and Abdominal Radiology (ESGAR), European Association for Endoscopic Surgery and other Interventional Techniques (EAES), International Society of Digestive Surgery,European Federation (EFISDS) and European Society of Gastrointestinal Endoscopy (ESGE). Eur Radiol. 2017;27(9):3856-66. 